\title{
STUDIES ON THE DEVELOPMENT OF THE IMPLANTATION REACTION IN THE MOUSE UTERUS: INFLUENCE OF ACTINOMYCIN D
}

\author{
C. A. FINN AND J. C. S. BREDL \\ Department of Physiology, Royal Veterinary College, London $\mathcal{N W 1} 0 T U$
}

(Received 21st June 1972)

\begin{abstract}
Summary. The influence of actinomycin D on the implantation of blastocysts has been studied in mice. The early stages of implantation, the Pontamine sky blue reaction and stromal oedema take place normally and the blastocyst is stimulated to develop. Decidualization, however, is delayed and the degeneration of the uterine epithelium around the blastocyst is inhibited, suggesting that the latter is dependent on DNA-directed messenger RNA synthesis whereas the initial implantation changes and activation of the blastocyst are not.
\end{abstract}

\section{INTRODUCTION}

During implantation in rodents, the endometrium undergoes a characteristic series of reactions (Krehbiel, 1937). One of the first to be detected upon contact of the blastocysts with the epithelial surface of the uterus is increased permeability of the stromal blood vessels and oedema of the stroma surrounding the blastocyst (Finn \& McLaren, 1967). This can be demonstrated by the intravenous injection of Pontamine sky blue before autopsy, when blue bands (the blueing reaction) distinguish those areas of the uterus containing implanting blastocysts (Psychoyos, 1961). At the same time, the surfaces of the uterine epithelium and trophoblast lose their microvilli and become closely apposed. Mayer, Nilsson \& Reinius (1967) refer to this as the attachment stage of implantation. Subsequently, the stromal cells immediately surrounding the blastocyst are transformed into decidual cells and the fibroblasts further out undergo mitosis (Finn \& Martin, 1967). This is followed by degeneration of the epithelial cells in contact with the blastocyst and their phagocytosis by the trophoblast.

The cause of the degeneration of the uterine epithelium has been widely disputed and is still not settled (Blandau, 1961). Recent evidence favours the view that the death of the cells is an integral part of the response of the endometrium to an implanting blastocyst and is not caused directly by trophoblast invasion (Finn \& Hinchliffe, 1964). Cell death is known to play an important part in some morphogenic processes during development and to be controlled by the genetic material in the nucleus (Saunders, Gasseling \& Saunders, 1962).

The antibiotic, actinomycin $\mathrm{D}$, affects many morphogenic processes by inhibiting the transcription of the information on the gene. When given before 
implantation, it prevents pregnancy and also inhibits the formation of decidual cells in response to an artificial stimulus such as the intrauterine injection of oil (Finn \& Martin, 1972) or trauma (Glasser, 1965). Detailed study of the effect of the drug on the decidual response in ovariectomized, hormone-treated mice showed that the first stages of the decidual reaction, which are characterized by increased permeability and stromal oedema, took place at the usual time but that the transformation of the stromal cells into decidual cells was inhibited as was the associated mitosis of the outer stromal cells. However, if the correct hormonal conditions were maintained, decidual transformation eventually took place after a delay of about $30 \mathrm{hr}$ and decidualization continued.

In the present work, we have investigated in more detail the effect of actinomycin $\mathrm{D}$ on the early morphological response of the uterine epithelium to an implanting blastocyst. To avoid any effect of the drug on organs concerned in pregnancy apart from the uterus, for example the ovaries, pituitary or hypothalamus, and to be able to control the timing of injections relative to implantation more precisely, pregnant mice were ovariectomized early in pregnancy and implantation was induced and maintained with exogenous ovarian hormones. Subsequently, in order to differentiate between any effect of the drug on the blastocyst and the uterus, experiments were designed involving the transfer of blastocysts between animals.

\section{MATERIALS AND METHODS}

Random-bred albino mice were kept under controlled lighting conditions, with an 8 -hr dark period ending at 12.00 hours. They were mated in the normal way and then ovariectomized through a dorsal incision approximately $72 \mathrm{hr}$ after mating. Progesterone $(500 \mu \mathrm{g})$ was injected subcutaneously soon after ovariectomy and then daily until autopsy. To precipitate implantation, a single injection of $20 \mathrm{ng}$ oestradiol-17 $\beta$ (nidatory oestrogen) was administered on the day after ovariectomy.

In experiments involving the transfer of blastocysts, the pregnant donor mice were given $500 \mu \mathrm{g}$ progesterone after ovariectomy. The blastocysts were flushed out the following day and were immediately transferred to the recipients, using the technique of McLaren \& Michie (1956). The recipients were ovariectomized virgin animals treated with hormones on the following schedule: Days 1 to $3,100 \mathrm{ng}$ oestradiol daily; Days 7 to $10,500 \mu \mathrm{g}$ progesterone $+10 \mathrm{ng}$ oestradiol; Day 11 onwards, $500 \mu \mathrm{g}$ progesterone.

With this hormone regimen, the uterus becomes sensitive and will allow implantation following transfer of blastocysts on Day 10, 4 to $6 \mathrm{hr}$ after the hormone injections. Actinomycin D (15 $\mu$ g dissolved in $0.1 \mathrm{ml}$ distilled water) was given by intraperitoneal injection at the specified times and the animals were killed at various intervals thereafter. In some experiments, the animals were given $0.1 \mathrm{mg}$ colchicine $2 \mathrm{hr}$ before autopsy and, in all experiments, $0.3 \mathrm{ml}$ of a $1 \%$ solution of Pontamine sky blue was injected intravenously $15 \mathrm{~min}$ before autopsy. The uteri were dissected out and fixed in Carnoy's fluid. After clearing in cedar-wood oil, blue bands were visible across the uteri indicating the position of implanting blastocysts. These areas were embedded in wax and at 
least one area from each uterus was serially sectioned. In some cases, the animals were perfused with fixative for electron microscopy (Finn \& Lawn, 1967), and blue areas were embedded in Araldite. Thick sections from these tissues gave very good definition under the light microscope.

\section{RESULTS}

Experiments involving ovariectomized, hormone-treated pregnant animals

In the first experiment, actinomycin D was given $6 \mathrm{hr}$ (five mice) or $1 \frac{1}{2} \mathrm{hr}$ (four mice) before, or $1 \frac{1}{2} \mathrm{hr}$ (fourteen mice) after the nidatory oestrogen injection and the mice were killed $24 \mathrm{hr}$ later. Blue areas were found in eight out of nine of the animals treated with actinomycin $\mathrm{D}$ before nidatory oestrogen, in all fourteen given actinomycin $\mathrm{D}$ after the nidatory oestrogen, and in all nine of the control animals.

Histological examination of the treated animals did not reveal any differences between those given actinomycin $\mathrm{D}$ before the nidatory oestrogen and those to whom it was given subsequently.

It is apparent that actinomycin D does not prevent the sensitization of the uterus or the early response to the blastocyst. This agrees with the similar finding using the artificial oil decidual stimulus.

Compared with the controls examined at this time, the most striking difference in the uteri of the treated animals was the complete absence of mitosis in the stroma, once again agreeing with the earlier findings in the oil-injection experiments. The blastocysts from the treated animals did, however, show evidence of mitosis and were of similar size to those in the control uteri. This suggests either that the actinomycin $\mathrm{D}$ does not pass into the blastocyst or that mitosis in the blastocyst is unaffected by it. The former seems more likely. Furthermore, it demonstrates that the influence of the oestrogen-activated uterus in stimulating the development of the ovum beyond the blastocyst stage is not inhibited by actinomycin $D$.

At this stage in both the control and the treated animals, the epithelium was intact and columnar (Pl. 1, Figs 1 and 2). The stromal cells of the control sites showed early signs of decidualization around the implanting blastocyst (Pl. 1, Fig. 1) with much mitosis in the outer regions. The uterine glands were usually confined to the outer areas. The treated animals showed some lining up of stromal cells around the implanting blastocyst, a feature frequently noted in very early implantation sites, but decidualization had not taken place and glands were still present throughout the stroma.

\section{Animals killed $48 \mathrm{hr}$ after nidatory oestrogen}

Thirteen animals given actinomycin D were examined $48 \mathrm{hr}$ after the nidatory oestrogen. Four of the animals received the actinomycin $1 \frac{1}{2} \mathrm{hr}$ before the oestrogen and nine of them $1 \frac{1}{2} \mathrm{hr}$ after it. Seven control animals were examined at the same time.

Control animals killed $48 \mathrm{hr}$ after the nidatory oestrogen showed clearly visible blue swellings in the uterus. Animals given actinomycin D $1 \frac{1}{2} \mathrm{hr}$ before or $1 \frac{1}{2} \mathrm{hr}$ after the oestrogen showed blue bands but very little swelling of the 
wall of the uterus. There was no discernible difference in the histological picture between the animals receiving the actinomycin $\mathrm{D}$ before or after the oestrogen. Stromal mitosis was still absent in the treated animals although there was some evidence of early decidual changes immediately surrounding the blastocyst (Pl. 2, Fig. 4). Glands were still present throughout the stroma of the treated animals whereas, in the controls, the stroma was decidualized except for a small area around the periphery, in which a few glands could be found (Pl. 2, Fig. 3).

The epithelium surrounding the blastocysts in the control uteri had disappeared so that the trophoblast cells were in contact with the decidual cells (Pl. 2, Fig. 3 and Pl. 3, Fig. 5). In some cases, the decidual cells had spread to surround the blastocyst. In the treated animals, the epithelial cells were still present around the blastocyst and had undergone a characteristic change. Several layers of epithelial cells were present, giving the appearance of stratified epithelium. The individual cells were rounded in cross-section and contained large droplets of fat. In most cases, therefore, the blastocyst was separated from the stroma by several layers of epithelial cells. Sometimes the blastocyst had penetrated through the epithelium at one point (Pl. 3, Fig. 6 and Pl. 4, Fig. 7).

At $48 \mathrm{hr}$, the blastocysts in the treated animals had developed beyond the stage seen at $24 \mathrm{hr}$ and mitoses were present in the cells. The trophoblast cells were very much thicker than in the controls and the embryonic cells did not appear as well organized (Pl. 3, Fig. 6 and Pl. 4, Figs 7 and 8).

\section{EXPLANATION OF PLATES}

\section{PLATE 1}

Photomicrographs of cross-sections of mouse uteri, showing implanting blastocysts $24 \mathrm{hr}$ after the initiation of implantation by oestradiol.

Fig. 1. From a control animal, showing attachment of the blastocyst to the uterine epithelium and early decidual reaction in the stroma. $\times 375$.

Fig. 2. From an animal treated with actinomycin D $22 \frac{1}{2} \mathrm{hr}$ earlier. The blastocyst appears to have attached normally and there is some lining up of stromal cells but no decidual reaction. $\times 375$.

\section{PLATES 2, 3 AND 4}

Photomicrographs of cross-sections of mouse uteri, showing implanting blastocysts $48 \mathrm{hr}$ after initiation of implantation.

Fig. 3. From a control animal. The epithelium surrounding the blastocyst has disappeared and an intense decidual reaction is present in the stroma. $\times 90$.

FIG. 4. From an animal treated with actinomycin D $46 \frac{1}{2} \mathrm{hr}$ earlier. The epithelium is intact and stratified and there is only a slight decidual reaction in the stroma with oedema around the periphery. $\times 90$.

FIG. 5. From a control animal, showing complete absence of uterine epithelium and very thin trophoblast in contact with the well-developed decidual cells. $\times 310$.

Fig. 6. From an actinomycin-treated animal. The build-up of the uterine epithelium around the blastocyst is clearly seen except at one point (indicated by the arrow) where the trophoblast appears to be penetrating through the epithelium. A depleted gland (G) is shown. $\times 250$.

Fig. 7. From an animal treated with actinomycin $D$, showing the penetration of the trophoblast more clearly. $\times 310$.

FIG. 8. From an animal treated with actinomycin $D$, showing the build-up of epithelium and thinning of the trophoblast clearly and the secretion (S) which is sometimes found, especially in the transferred sites. $\times 356$. 
ar y

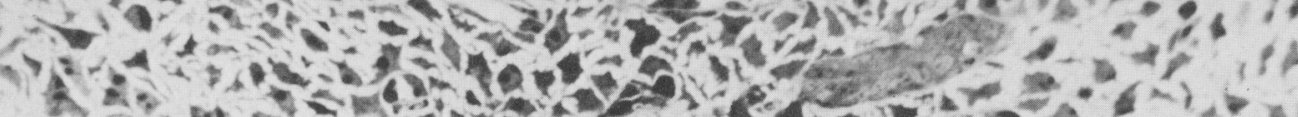

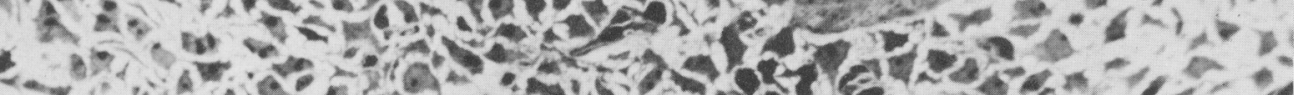

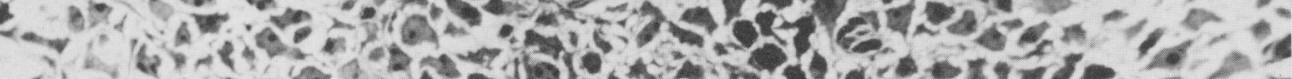

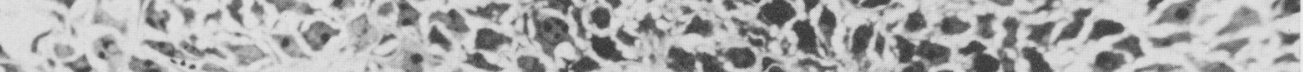

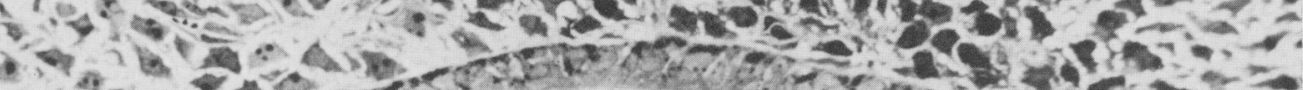
ro.

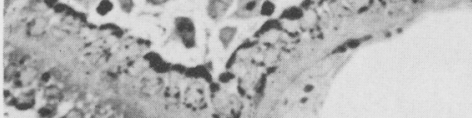

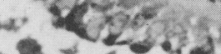

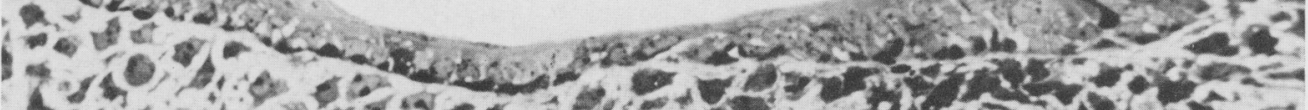

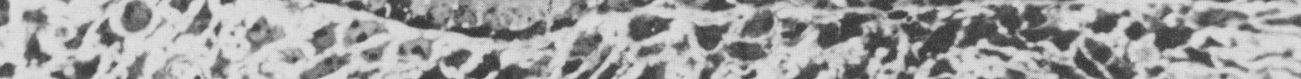
-

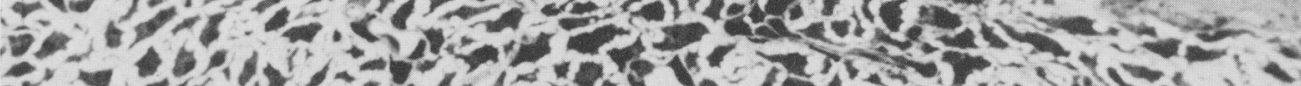

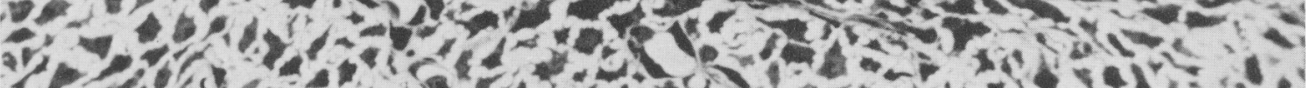

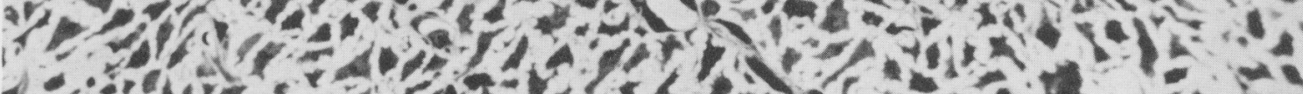

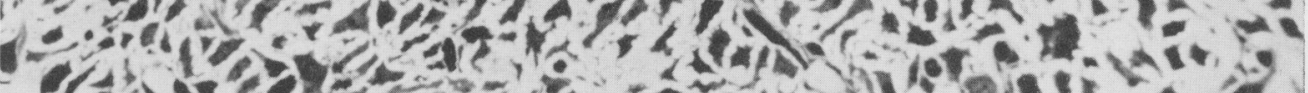

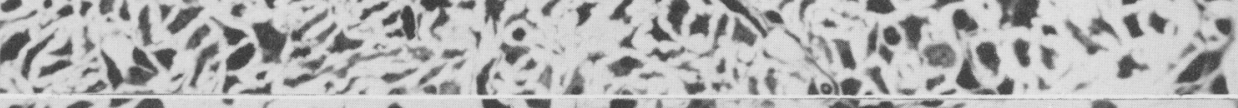

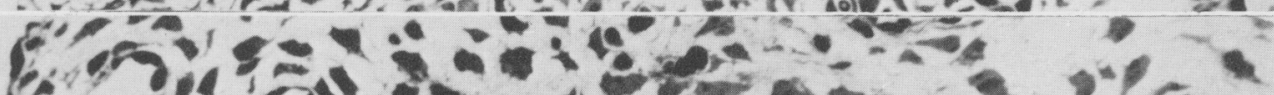

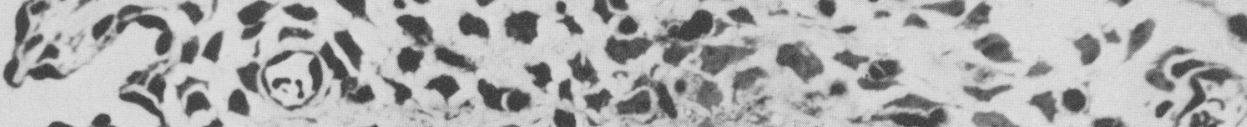

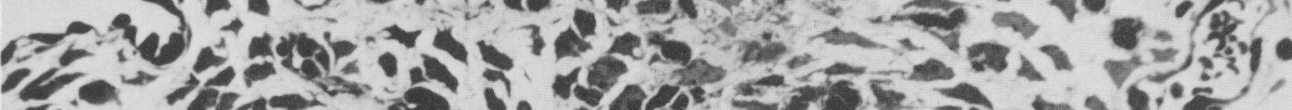

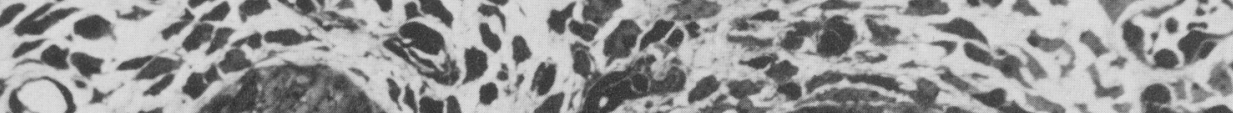
(1)

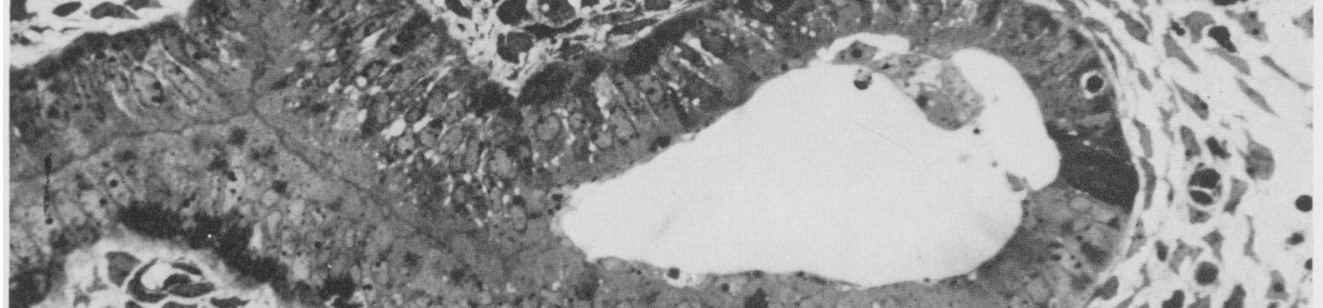

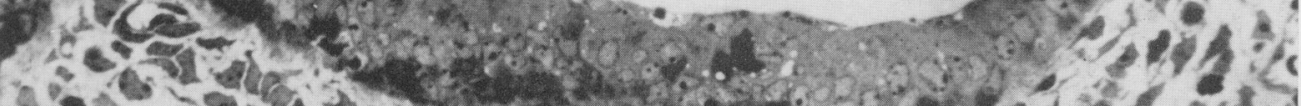

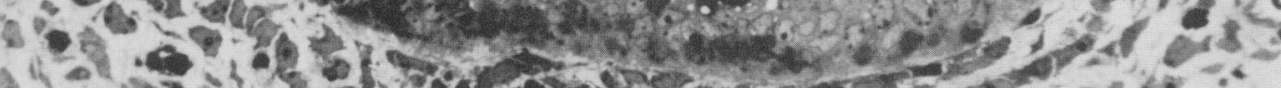

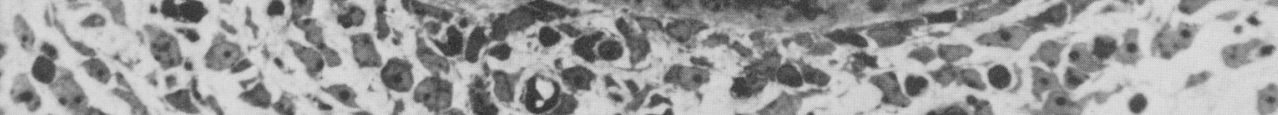
T. is

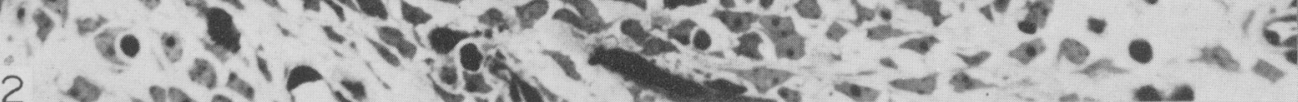




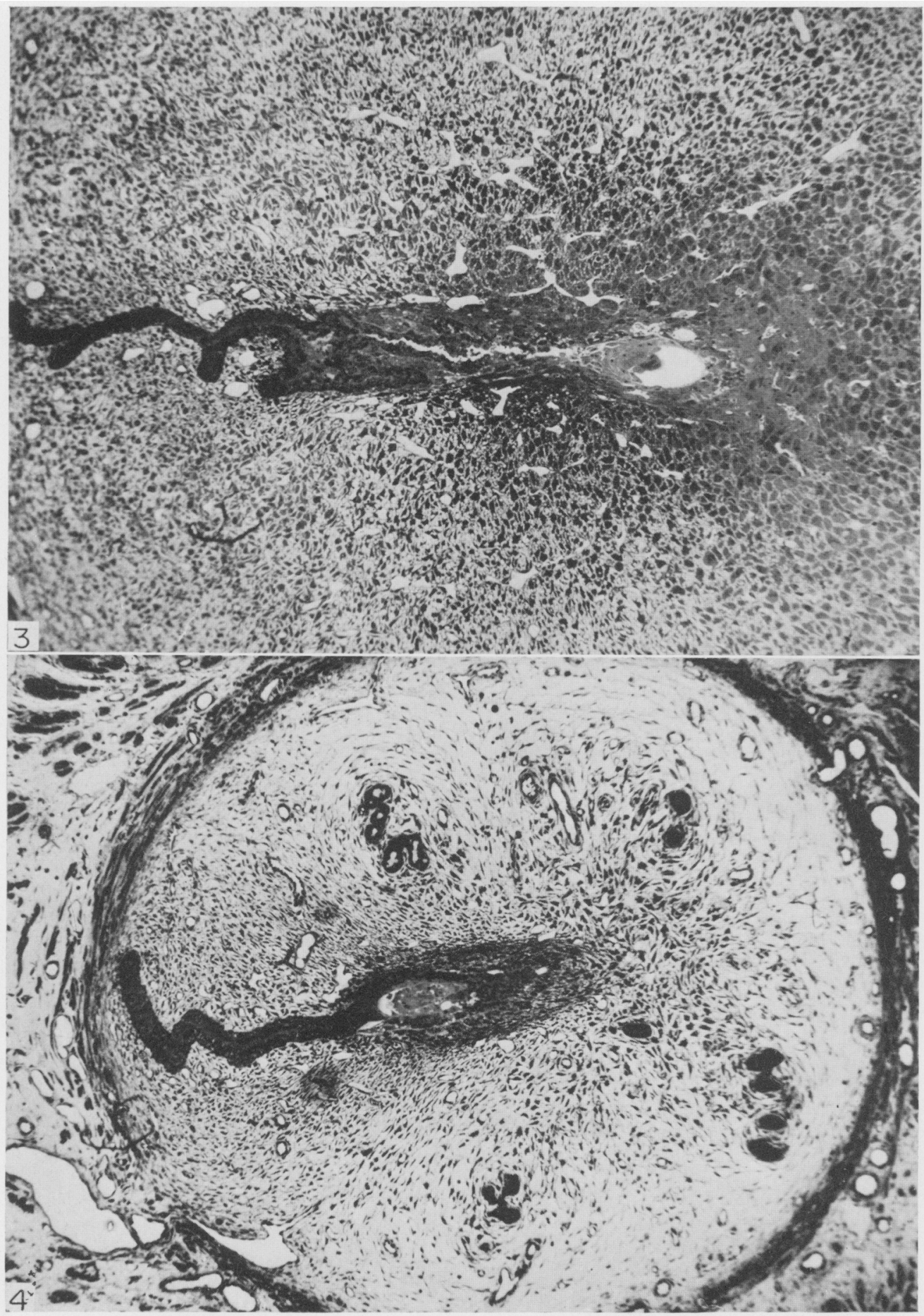




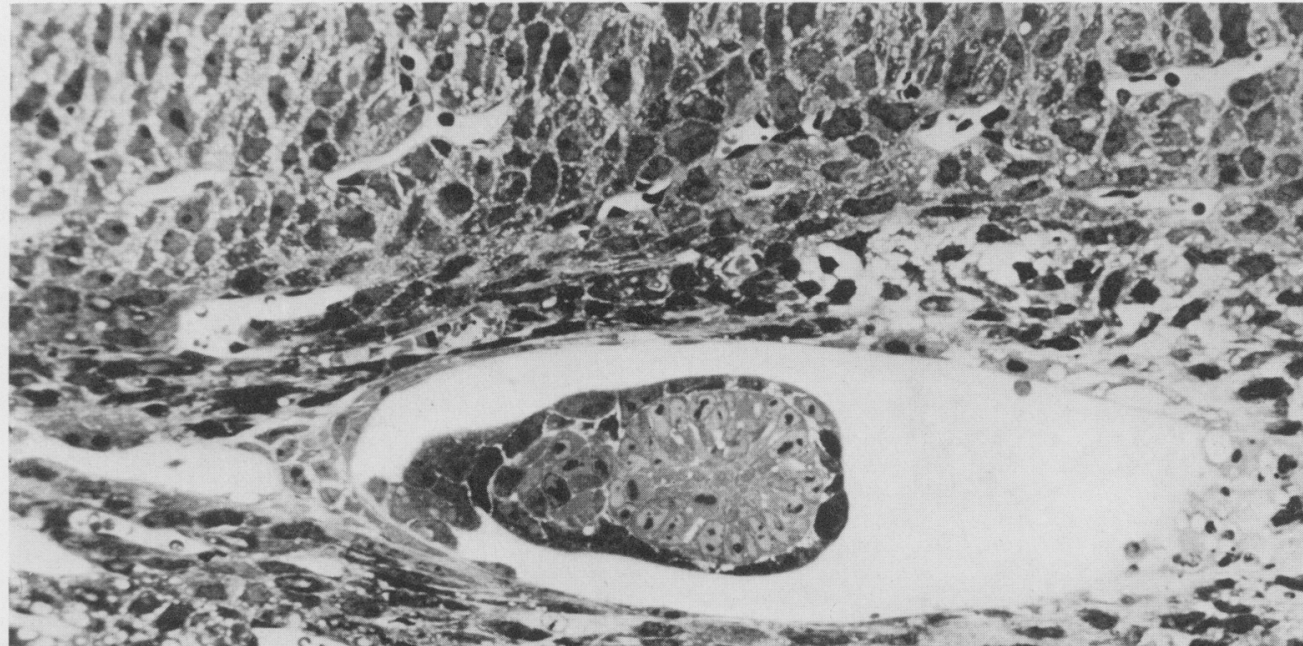

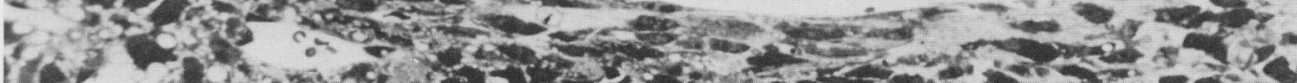

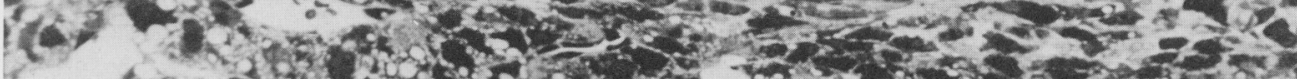

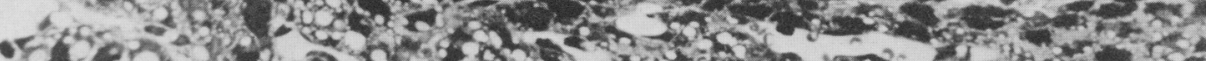
7 - If

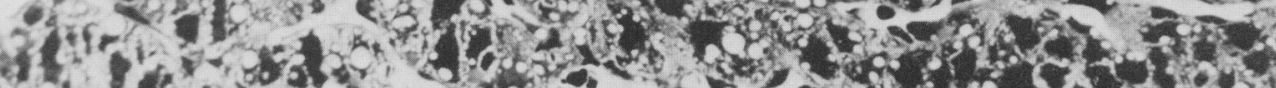

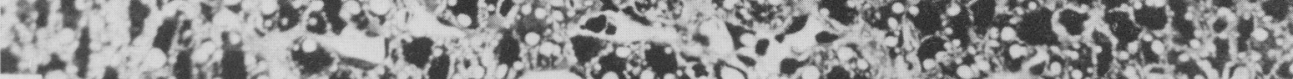

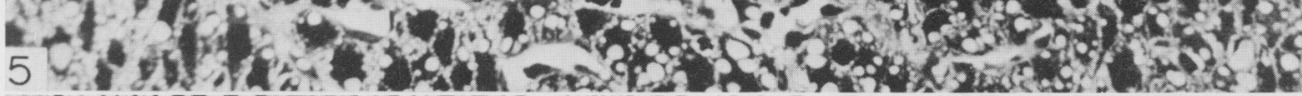

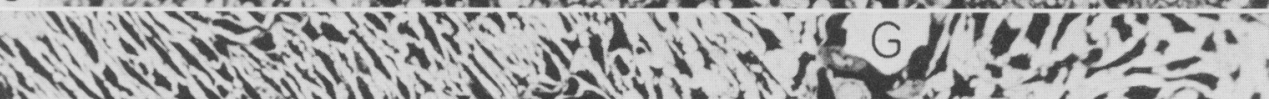
M. N.

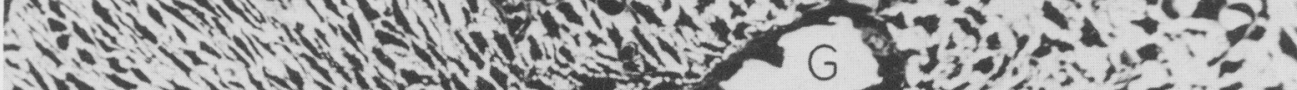

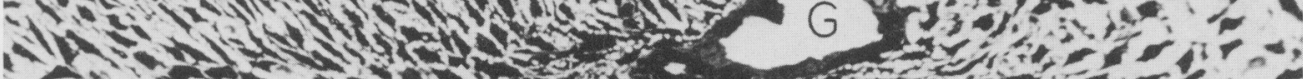

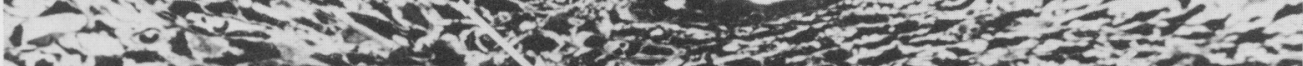

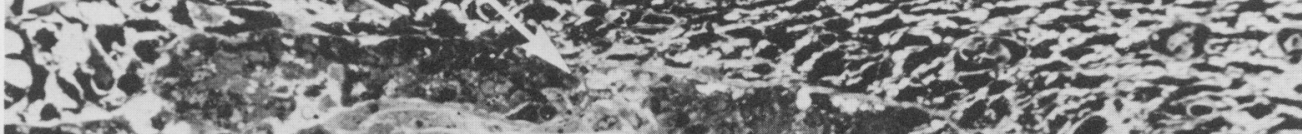

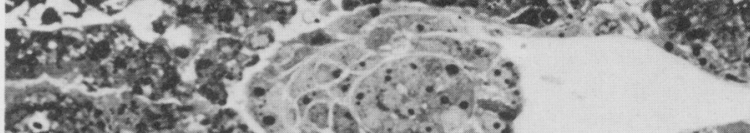

C.

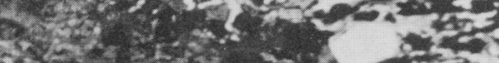

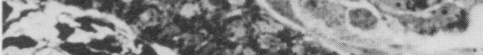

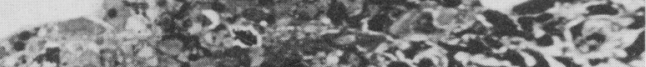

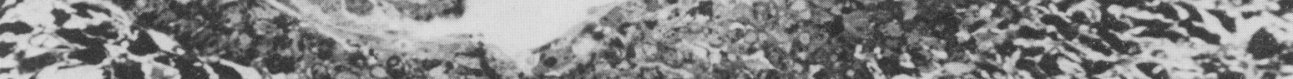

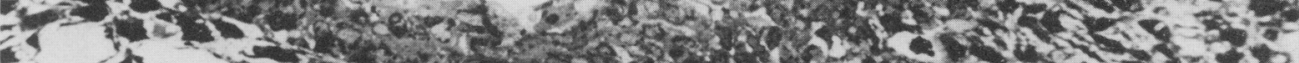

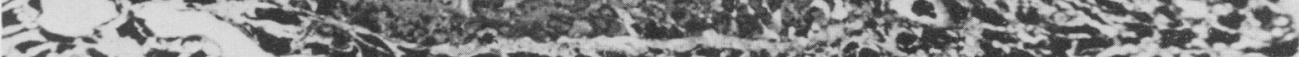

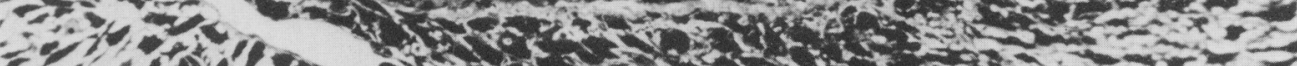

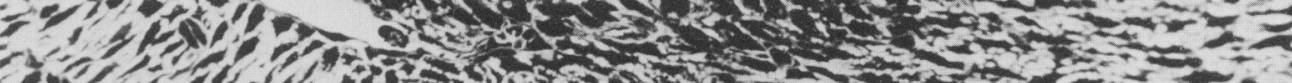

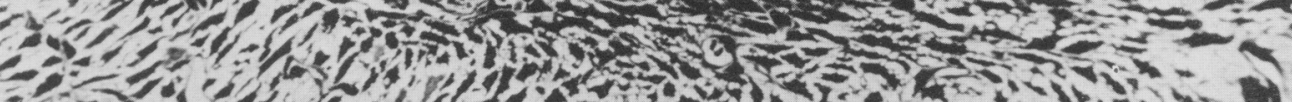

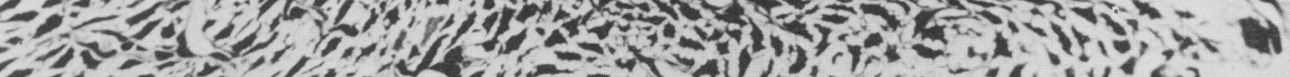

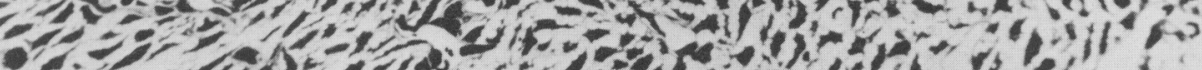

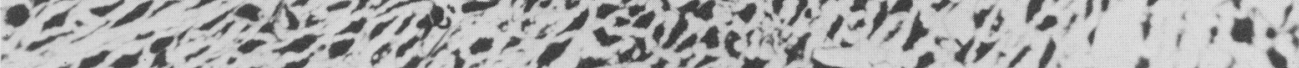

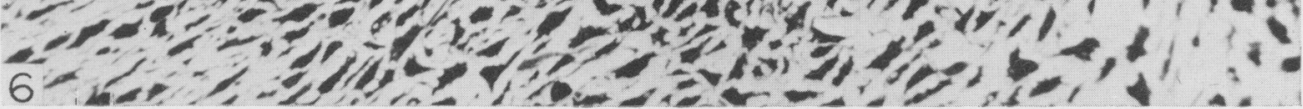




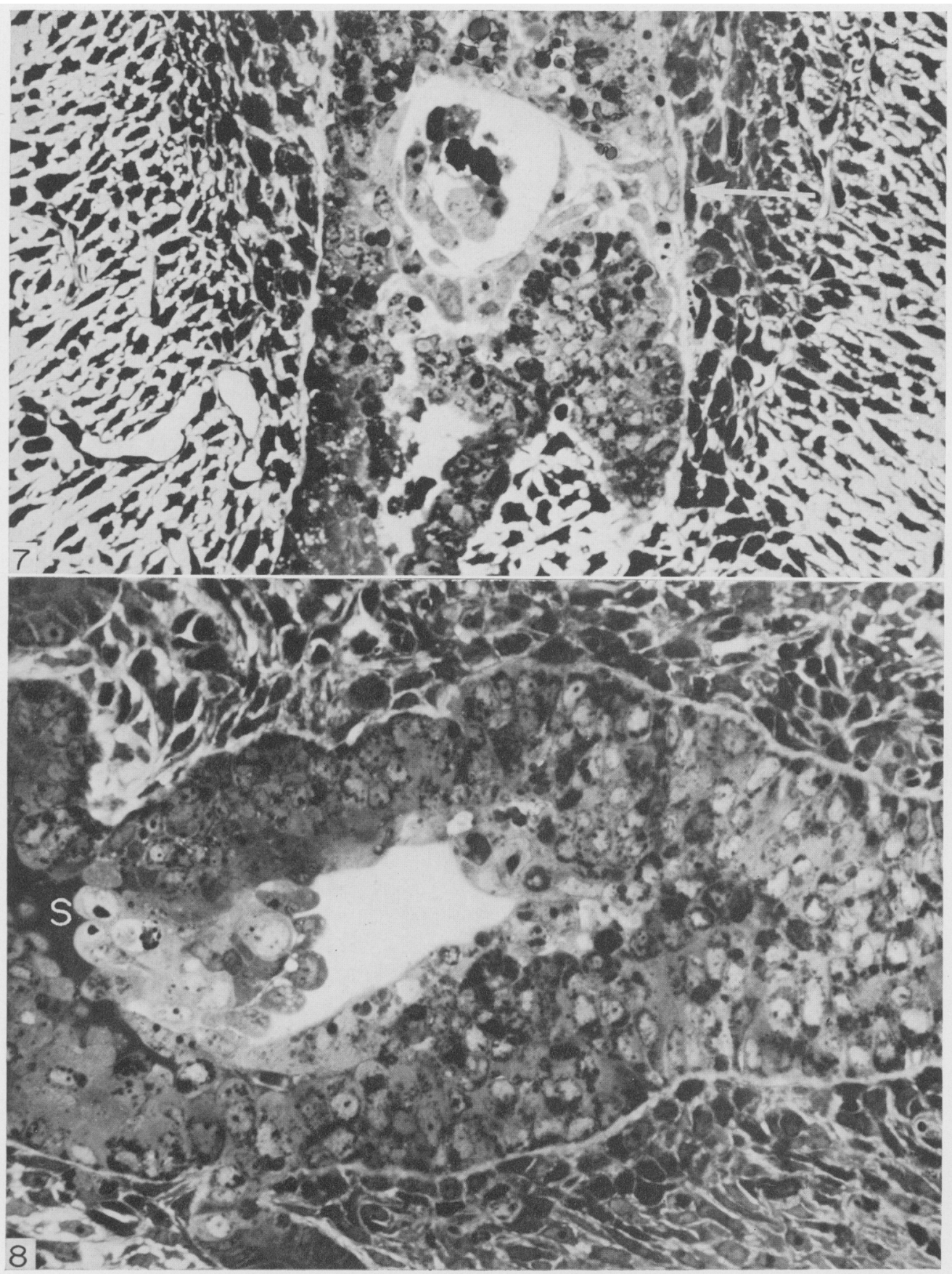


Some of the glands of the treated animals showed a very characteristic appearance, especially in the Araldite-embedded material. This is shown in Pl. 3, Fig. 6. The epithelial cells lining the glands were low and the gland lumen was large. This appearance suggests that the gland had been exhausted of its secretion. Associated with this was the occasional finding of a secretion surrounding the blastocyst. This stained intensely with the azure blue used on the Araldite-embedded sections (Pl. 4, Fig. 8) and reacted positively with periodic acid Schiff stain on the wax-embedded material. Little secretion was seen in the control uteri in which the glands had largely disappeared from around the blastocyst owing to the massive decidual development.

\section{Experiments involving transfer of blastocysts}

The build-up of epithelium shown in the first experiments could be due to inhibition by actinomycin $\mathrm{D}$ of the intracellular mechanisms controlling the cell death in the uterine epithelium or, alternatively, the drug might be affecting the blastocyst and in some way inhibiting the trophoblastic invasion of the epithelial cells. Although the latter seemed unlikely in view of the failure of the drug to prevent the growth and development of the blastocyst, further experiments were carried out in which the effect of the drug on the uterus was separated from any possible effect on the blastocyst, using the technique of blastocyst transfer.

Three treatment groups were investigated. In the first, the donor animals received actinomycin D $4 \mathrm{hr}$ before transfer of the blastocysts whilst the recipients were untreated. In the second, the recipients received actinomycin D $4 \mathrm{hr}$ before the transfer of blastocysts from untreated donors while, in the final group, neither donors nor recipients received the drug.

Animals were examined 24 and $48 \mathrm{hr}$ after transfer. Those in which the blastocysts were transferred from mice treated with actinomycin D were in all respects similar to those in the control group, which did not differ from the control animals in the first experiment. When blastocysts were transferred from untreated animals to treated recipients, the implantation sites resembled those of the treated animals in the first experiment, with development of the blastocyst and build up of the uterine epithelium.

From these results, it is clear that the failure of the uterine epithelium to degenerate and be phagocytosed by the trophoblast is caused by the action of actinomycin $\mathrm{D}$ in the uterus, and not due to any effect on the blastocyst.

\section{DISCUSSION}

These results provide evidence in favour of the view that the breakdown of the uterine epithelium around the blastocyst in the mouse, and probably in other species which implant eccentrically, is controlled by information contained in the DNA of the epithelial cells. This is released during implantation, probably by way of the transcription of DNA through messenger RNA. In many other species (e.g. horse and pig), there is no breakdown of the epithelium and the trophoblast does not pass into the stroma whilst, in a few including the human, the blastocyst appears to pass between the epithelial cells into the stroma. In 
this interstitial type of implantation, it is thought that the trophoblast penetrates the epithelium by virtue of its invasive properties (Amoroso, 1952).

It was of considerable interest in the present experiments to find frequently that the trophoblast had penetrated the epithelium at one point. This suggests that, in the mouse, the trophoblast is capable of active invasion when presented with an intact epithelium, although normally the epithelial breakdown makes this unnecessary.

The increasing complexity of the mode of implantation from the simple apposition of the trophoblast against the uterine epithelium, seen, for example, in the pig and horse, to the embedding of the blastocyst within the stroma, has probably evolved by acquisition of two properties; invasiveness of the trophoblast and degeneration of the uterine epithelium. In the present experiments, we have shown that maternally administered actinomycin D can inhibit the latter but not the former. This probably indicates failure of the drug to pass through the barrier presented by the maternal epithelium rather than lack of effect on the blastocyst.

The build-up of the epithelium around the blastocyst is difficult to explain. The only naturally occurring condition resembling this is the epithelial plaque formation found at the implantation site in rhesus monkeys. Speculation on the cause of the condition would at present be premature.

The finding in these experiments, as in the earlier ones on the decidual cell reaction, that the early stages of the implantation reaction (Pontamine sky blue and stromal oedema) are not inhibited by actinomycin D, even when given $1 \frac{1}{2} \mathrm{hr}$ or $6 \mathrm{hr}$ before the nidatory oestrogen, suggests that, although these reactions are oestrogen-dependent, they are not controlled by RNA. The mechanism of action of oestrogen in these circumstances is obscure.

Other responses of oestrogen are inhibited by actinomycin $\mathrm{D}$ and there is good evidence that the mode of action is by way of the production of DNAdependent RNA. Possibly oestrogens have two mechanisms of action: one acting through the genome and one through some other mechanism. There have been suggestions that cyclic AMP may be involved. Stimulation of the blastocyst to continue its development is included among the early implantation reactions. The nature of the stimulus given by the uterus is unknown although it is known to be oestrogen-dependent in the rat and mouse. The present results suggest that it is not dependent on DNA-directed RNA synthesis and is in some way related to the very early implantation changes in the uterus.

\section{AGKNOWLEDGMENTS}

We are pleased to acknowledge the financial support of the Wellcome Trust, and the technical assistance of Mrs J. Downie, Miss G. Blair and Mr J. Lewin. We also thank Mr D. Woulds for taking the photographs.

\section{REFERENGES}

Amoroso, E. C. (1952) Placentation. In: Marshall's Physiology of Reproduction, 3rd edn, Vol. 2, p. 127. Ed. A. S. Parkes. Longmans Green, London. 
BLANDAU, R. J. (1961) Biology of eggs and implantation. In: Sex and Internal Secretions, 3rd edn, Vol. 2, p. 797. Ed. W. G. Young. Baillière, Tindal \& Cox, London.

FinN, C. A. \& Hinchliffe, J. R. (1964) The reaction of the mouse uterus during implantation and deciduoma formation as demonstrated by changes in the distribution of alkaline phosphatase. 7. Reprod. Fert. 8, 331.

FinN, G. A. \& LAwN, A. M. (1967) Specialized junctions between decidual cells in the uterus of the pregnant mouse. F. Ultrastruct. Res. 20, 321.

Finn, C. A. \& McLaren, A. (1967) A study of the early stages of implantation in mice. F. Reprod. Fert. 13, 259.

Finn, C. A. \& Martin, L. (1967) Patterns of cell division in the mouse uterus during early pregnancy. 7. Endocr. 39, 593.

FinN, C. A. \& MARTIN, L. (1972) Temporary interruption of the morphogenesis of deciduomata in the mouse uterus by actinomycin D. F. Reprod. Fert. 31, 353.

GLASSER, S. R. (1965) Biochemical studies on a cellular receptor mechanism for uterine sensitivity. Excerpta med. Int. Congr. Series, 99, 335.

KREHBieL, R. H. (1937) Cytological studies of the decidual reaction in the rat during early pregnancy and in the production of deciduomata. Physiol. Zoöl. 10, 212.

McLaren, A. \& Mrchie, D. (1956) Studies on the transfer of fertilized mouse eggs to uterine foster mothers. I. Factors affecting the implantation and survival of native and transferred eggs. 7. exp. Biol. 33, 394.

MAYER, G., NiLsson, O. \& ReInIus, S. (1967) Cell membrane changes of uterine epithelium and trophoblast during blastocyst attachment in rat. Z. Anat. EntwGesch. 126, 43.

Psychoyos, A. (1961) Permeabilité capillaire et décidualization utérine. C.r. hebd. Séanc. Acad. Sci., Paris, $252,1515$.

Saunders, J. W., JR, Gasseling, M. T. \& Saunders, L. C. (1962) Cellular death in morphogenesis of the avian wing. Devl Biol. 5, 147. 